Review

www.mdpi.com/journal/remotesensing

\title{
Detection and Measurement of Snowfall from Space
}

\section{Vincenzo Levizzani *, Sante Laviola and Elsa Cattani}

National Research Council of Italy, Institute of Atmospheric Sciences and Climate (CNR-ISAC), via Gobetti 101, Bologna, Italy; E-Mails: s.laviola@isac.cnr.it (S.L.); e.cattani@isac.cnr.it (E.C.)

* Author to whom correspondence should be addressed; E-Mail: v.levizzani@ isac.cnr.it; Tel.: +39-051-639-8015; Fax: +39-051-639-9658.

Received: 21 November 2010; in revised form: 5 January 2011 / Accepted: 5 January 2011 / Published: 11 January 2011

\begin{abstract}
Snowfall detection and measurement represent highly difficult problems in modern hydrometeorology. Ground measurements are complicated due to detection technology limitations, snow drift and accumulation issues, and error definition. The snowfall detection from space is in turn affected by all detection limitations that characterize the measurement of rainfall with the addition of several complications, such as the indirect character of remote sensing precipitation estimation, the presence of frozen or snow-covered terrain, and the unknown vertical distribution of hydrometeors in the cloud column. Several methods for the retrieval of snowfall intensity from satellite have been proposed in recent times using passive and active sensors. No satisfactory answer to the general problem of quantitative snowfall intensity determination has been found to date, but several studies contribute to delineate a working framework for the future operational retrieval algorithms.
\end{abstract}

Keywords: snow; passive microwave; radar; satellite; water cycle

\section{Introduction}

The average annual precipitation on Earth is evaluated around $690 \mathrm{~mm}$ and snowfall accounts for about $5 \%$ of it. However, snow is a predominant component of the global precipitation amount at mid and high latitudes. In fact, above 60-70 degrees it dominates over the liquid precipitation [1] as shown in Figure 1. The quantitative determination of snowfall intensity from space is thus crucial when aiming at a global estimation coverage. Note that the areas where snowfall is predominant are generally 
remote and not adequately instrumented for precipitation measurements at the ground, which is very problematic to achieve [2].

Figure 1. Mean zonal occurrence of oceanic light precipitation (as a percentage of total rainfall occurrence) derived from the Comprehensive Ocean-Atmosphere Data Set (COADS) using ship-borne meteorological observations (1958-1991). The latitude ranges on top refer to the coverage of current or proposed satellite missions: European contribution to GPM (EGPM), Global Precipitation Measurement (GPM) mission core satellite, and Tropical Rainfall Measuring Mission (TRMM). (courtesy of C. Kidd, University of Birmingham [3]).

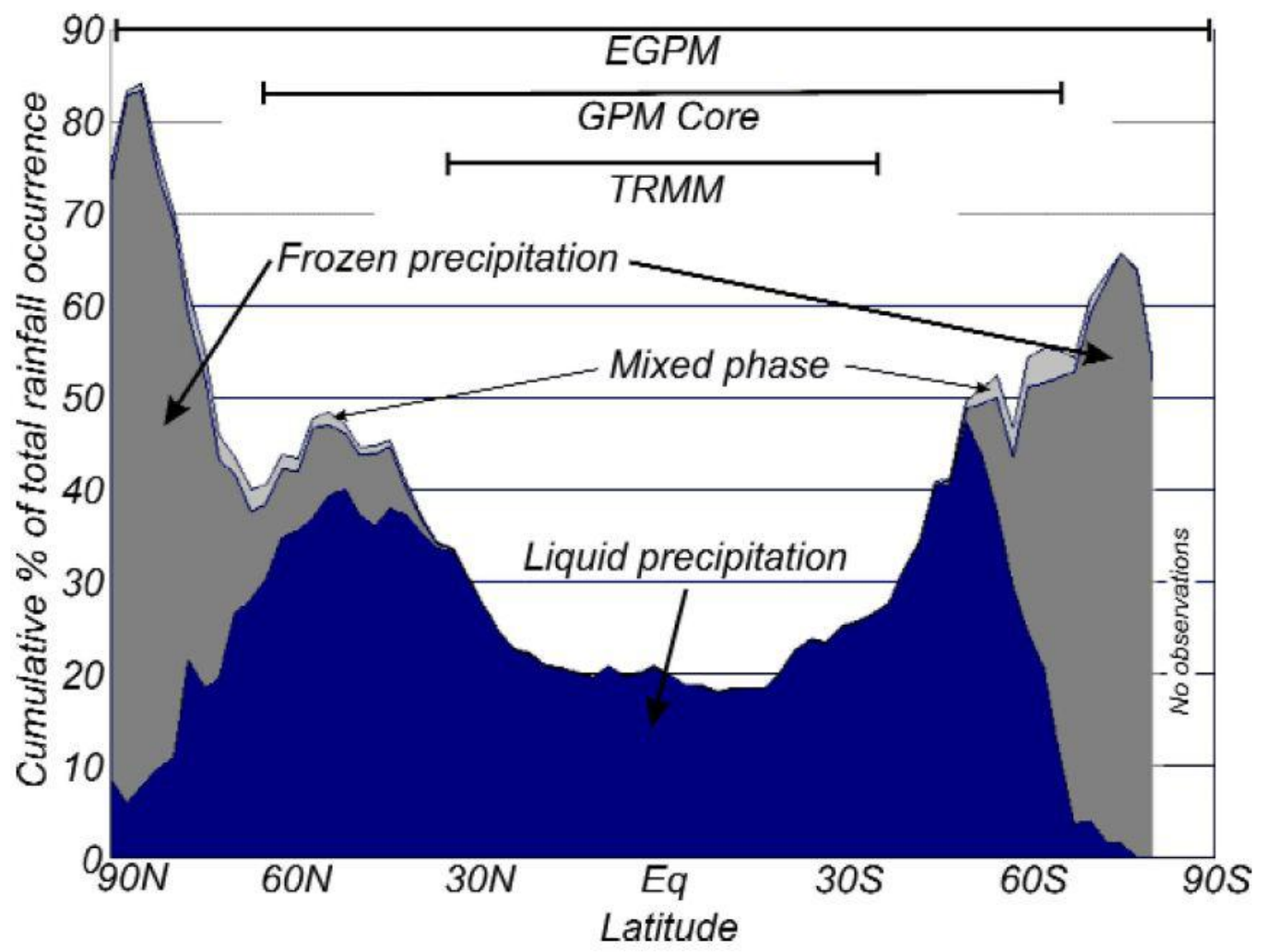

Over the last twenty years several algorithms were proposed using passive microwave (PMW) satellite sensors to estimate precipitation intensity from space (see [4-7] for an overview of the methods), but they were mostly conceived for rainfall retrieval. The algorithms are essentially based on two different approaches: Scattering and absorption of radiation by precipitation hydrometeors. The scattering algorithms take advantage of the scattering properties of hydrometeors within the atmospheric window channels in the satellite field of view (FOV). The absorption-based methods derive precipitation parameters from the emission of hydrometeors in atmospheric window (e.g., detection of warm rain over ocean) and/or in the proximity of strong gaseous (e.g., water vapor) absorption bands.

The following are the main reasons behind the general lack of algorithms for snowfall detection and estimation:

1. Ice hydrometeors are scarcely distinguishable from water drops in the visible and infrared spectral channels, while in the PMW the snow signal below $90 \mathrm{GHz}$ is quite weak. This leads to 
considering frequencies above $100 \mathrm{GHz}$ as candidates for snowfall retrievals. The latter are hosted onboard a limited number of missions that were only launched in recent times.

2. The radiative properties of snowflakes and ice crystals are much more complex than those of water droplets due to the inherent non-sphericity of the ice hydrometeors (e.g., [8,9]). Moreover, the thermal emission of water vapor and of water clouds often mask the scattering from snow thus reducing the snowfall signal [10]. The dimensions and aggregation modes of ice crystals in natural clouds [11] are also not completely understood.

3. The vertical structure of ice clouds is scarcely known. Ice crystal concentrations are very variable with ice nuclei and environmental conditions (e.g., [12-14]) so that it is difficult to decide upon an unambiguous microphysical structure given a set of available PMW observations from space that necessarily refer to the whole atmospheric column.

4. Last but certainly not least is the problem of the understanding of snow microphysics in mixed clouds. The presence of super cooled water poses problems when trying to untangle the radiative contributions of water and ice for snowfall detection from the ground and from space. First the microphysics of super cooled water is not completely understood (e.g., temperature range), and second, the uncertainties in the absorption of super cooled water are difficult to pinpoint due to the lack of laboratory measurements at frequencies above $10 \mathrm{GHz}$. Laboratory experiments and ground-based radiometer measurements were recently carried out for checking the ability of common dielectric models of liquid water for the simulation of microwave absorption of super cooled clouds [15], and for the improvement of the physical assumptions behind snowfall retrieval methods and numerical model parameterizations (e.g., [16]).

A review of the current literature on snowfall retrieval algorithms is presented hereafter starting from the studies on the spectral response of microwave channels to ice clouds (Section 2) and then continuing on the use of PMW frequencies and radar in space (Section 3). A discussion will be presented in Section 4 introducing needs for future research.

\section{Ice Cloud Structure and Response in the Microwaves}

\subsection{Ice Cloud Structure from Recent Field Studies}

Studies of the microphysical properties of ice clouds are rather difficult as they need to be conducted by means of aircraft penetrations in extreme conditions. Secondly, the cloud probes suited for such measurements, although their technology and data processing has registered considerable advances, are still subject to limitations as to their capacity of measuring realistic size distributions and shapes of the hydrometeors. An example of this fact are the interarrival time and the shattering that need to be accounted for when using the fast forward scattering spectrometer probe (FSSP) [17-19]. However, the last decade has registered considerable advances in measuring technology and campaigns were organized to characterize ice cloud structure for cloud parameterization and remote sensing applications.

About $90000 \mathrm{~km}$ of in cloud measurements were presented by Korolev et al. [20] for continental clouds between $-50<\mathrm{T}<0{ }^{\circ} \mathrm{C}$ finding that the effective dimension of hydrometeors is a weak function of temperature, and the effective concentration rapidly decreases with decreasing temperature between 
$-20<\mathrm{T}<+10{ }^{\circ} \mathrm{C}$, and then remains approximately constant between $-50<\mathrm{T}<-20{ }^{\circ} \mathrm{C}$. They also derived cumulative probability distributions of all relevant parameters characterizing the size distribution of ice hydrometeors for $\mathrm{St}, \mathrm{Sc}, \mathrm{Ns}, \mathrm{As}, \mathrm{Ac}, \mathrm{Ci}$, and $\mathrm{Cu}$ clouds; different regimes for cloud microstructure formation in the various cloud types were found.

Ice crystal number concentration $\left(\mathrm{N}_{\mathrm{i}}\right)$ is another important parameter that influences cloud optical and microphysical properties, as reported by Gultepe et al. [21]. They made observations in the glaciated regions of stratiform clouds during two Arctic and two mid-latitude field projects to study the $\mathrm{N}_{\mathrm{i}}-\mathrm{T}$ relationship. Scatter plots of $\mathrm{N}_{\mathrm{i}}-\mathrm{T}$ do not show a good correlation with $\mathrm{T}$ for ice crystals at sizes $<1000 \mu \mathrm{m}$. For a given $\mathrm{T}$, the variation of $\mathrm{N}_{\mathrm{i}}$ is found to be up to two to three orders of magnitude for ice crystals with sizes $>100 \mu \mathrm{m}$. A significant $\mathrm{N}_{\mathrm{i}}-\mathrm{T}$ relationship is found for precipitation sized particles with sizes $>1000 \mu \mathrm{m}$. The ice particle concentration for sizes between 100 and $1000 \mu \mathrm{m}$ varied from 0.1 to $100 \mathrm{~L}^{-1}$, independent of geographic location.

Studies of Korolev et al. [22] of mixed phase clouds in frontal systems have analyzed the ice water content (IWC) of clouds with total water content $(\mathrm{TWC})>0.01 \mathrm{~g} \mathrm{~m}^{-3}$. The ice-water fraction $\left(\mu_{3}=\right.$ IWC/TWC) had a minimum in the range $0.1<\mu_{3}<0.9$, and two maxima for liquid clouds $\left(\mu_{3}<0.1\right)$ and ice clouds $\left(\mu_{3}>0.9\right)$. The concentration of particles in glaciated clouds was found to be nearly constant at $2-5 \mathrm{~cm}^{-3}$ for $-35<\mathrm{T}<0{ }^{\circ} \mathrm{C}$. The concentration of droplets in liquid clouds decreased with decreasing $\mathrm{T}$. The mean volume diameter of particles in ice clouds varied between 20 and $35 \mu \mathrm{m}$, and in liquid clouds between 10 and $12 \mu \mathrm{m}$. Both IWC and liquid water content (LWC) decreased with decreasing $\mathrm{T}$.

Note that these studies are rather pioneering and describe only those cases encountered during the experiments without pretending to be general. Other studies are needed although the difficulty of their execution limits their planning.

\subsection{Ice Cloud Sensing in the Microwaves}

Pioneering observations of Wilheit et al. [23] uncovered the capabilities of the various PMW channels for cloud ice detection and precipitation potential. The sensitivity of PMW observations of precipitation to the ice particle size distribution variations was investigated by Bennartz and Petty [24]. The authors used a radiative transfer model for different precipitation rates and different hydrometeor types (snow, graupel and hail) to investigate the dependence of the optical properties on rain rate and radar reflectivity. Results show that, for a given rain rate, the variations of particle density and size may result in variation of the extinction coefficient by an order of magnitude while, for a broad range of particle sizes, the volume extinction coefficient is little affected by particle density in comparison with the liquid equivalent-size of the ice particles. A comparison of scattering indices at $85 \mathrm{GHz}$ derived from Special Sensor Microwave Imager (SSM/I) overpasses with those derived from model data showed that the size of the precipitating ice particles governs the variability of the scattering index thus hinting to differences based on the type of precipitating event.

Evans and Stephens [25,26] simulated the scattering properties of ice particles from 30 to $2000 \mu \mathrm{m}$ at 85.5, 157, 220 and $340 \mathrm{GHz}$ using five different shapes: Solid and hollow columns, hexagonal plates, planar bullet rosettes, and equivalent-volume spheres. Their results [25] indicate that the particle shape has significant effects: A range of about three is found in extinction over the five shapes 
for the same size distribution and IWC. The characteristic particle size has the greatest impact on the extinction and single scattering albedo while the distribution width plays a minor role. For the remote sensing of ice clouds [26] the key parameter is the sensitivity relating the modeled brightness temperature (TB) depression to the ice water path (IWP). The authors showed that, for higher frequencies or distributions of larger particles (scattering regime), the sensitivity is nearly independent of cloud temperature and of the structure of the atmosphere underneath. Single scattering properties of ice and snow were also simulated by Liu [27] at high frequencies between 85 and $220 \mathrm{GHz}$ using rosettes, sector snowflakes and dendrite snowflakes. Doherty et al. [28] found that the distribution and density of the ice particles significantly affect the interpretation of the sensor radiances using radiative transfer models such as the Radiative Transfer (RT) for the Television infrared observation satellite Operational Vertical Sounder (TOVS) (RTTOV, http://research.metoffice.gov.uk/research/ interproj/nwpsaf/rtm/index.html).

The response of PMW observations to ice particle scattering and surface emissivity was studied by Bennartz and Bauer [29] for the 85, 150, and $183 \mathrm{GHz}$ frequencies using two- and three-dimensional simulations of different precipitation events. The channel around $150 \mathrm{GHz}$ generally exhibits the strongest scattering signature due to precipitation sized ice particles and is only moderately affected by variations in surface emissivity. Channels around $85 \mathrm{GHz}$ are found much more affected by variable surface emissivity and show on average a 2 to 2.5 times smaller scattering signature. The authors find that the sensitivity of water vapor sounding channels at $183-7 \mathrm{GHz}$ to ice particle scattering strongly depends on the environmental conditions, but is in general about a factor of 1.5 to 2.5 smaller than at $150 \mathrm{GHz}$. This is due to the contribution of water vapor in and above the cloud to total emission, masking the scattering signal. Frequencies around $150 \mathrm{GHz}$ in combination with channels at 85 and 183-7 GHz seem thus most appropriate for the detection and retrieval of precipitation properties at middle and high latitudes.

Hong et al. [30] conducted a similar study on the sensitivity of PMW TBs between 89 and $190 \mathrm{GHz}$ to surface emissivity and hydrometeors. Their findings show that the window channel at $89 \mathrm{GHz}$ is dependent upon surface emissivity, while the three water vapor channels around $183 \mathrm{GHz}(183 \pm 1$, $183 \pm 3$ and $183 \pm 7$, from now on indicated as 184,186 and $190 \mathrm{GHz}$ ) are completely independent, and the window channel at $150 \mathrm{GHz}$ is nearly independent of the surface emissivity because of the atmospheric opacity at these frequencies. All channels are apparently influenced by deep convective clouds and their thick cirrus clouds. The channels at 89, 150, and $190 \mathrm{GHz}$ are strongly sensitive to variations in the LWC above $5 \mathrm{~km}$. The sensitivity of the $150 \mathrm{GHz}$ channel to liquid water is about twice that at $190 \mathrm{GHz}$. All channels are generally sensitive to variations in the frozen hydrometeor content at levels above $7 \mathrm{~km}$. The $184 \mathrm{GHz}$ channel shows virtually no influence from the frozen hydrometeors at levels below $7 \mathrm{~km}$. Weng and Grody [31] used the Microwave Imaging Radiometer (MIR) onboard the aircraft to measure radiances above ice clouds at 89, 150, 184, 186, 190 and $220 \mathrm{GHz}$. They concluded that the MIR frequencies were affected primarily by thick ice clouds such as cirrus anvil and convection. Over highly convective areas the measurements at 89 and $220 \mathrm{GHz}$ are more or less identical because of the scattering by large ice particles aloft that approaches the geometric optics limit, which is independent of wavelength. Under such conditions only the 89 and 150 
GHz channels are used to retrieve the particle effective size and IWP. However, the magnitude of the IWP remains uncertain because of insufficient information on the ice particle bulk density.

The above results point directly towards the use of PMW channels onboard the Advanced Microwave Sounding Unit-B (AMSU-B) [32] that hosts five channels at 89, 150, 184, 186 and $190 \mathrm{GHz}$. The sensor was initially designed for water vapor profile retrievals [33,34] and thus an assessment needs to be done of the impact of cold clouds on the tropospheric humidity in view of deriving cloud microphysical properties. Muller et al. [35] have demonstrated the impact of ice clouds at 157 and $183 \mathrm{GHz}$. Greenwald and Christopher [36] showed that over land and ocean the non-precipitating clouds have a measurable, although weak $(1.4 \mathrm{~K})$ impact on the depression of the TB at $183 \mathrm{GHz}$, while cold clouds associated with precipitation have a lager effect $(7 \mathrm{~K})$. This opens up the way to the estimation of clouds and precipitation physical properties.

Figure 2 graphically shows the properties of the AMSU-B channels. The $89 \mathrm{GHz}$ is a window channel and the signal is affected by the surface emissivity value, which is in turn influenced by surface roughness and temperature. The $150 \mathrm{GHz}$ is a window channel itself with its weighting function peaking near ground (e.g., [37]). The scattering is much more marked (see the depression of the TB in correspondence of convective clouds). The 184 and $186 \mathrm{GHz}$ channels measure the absorption of the atmospheric layers at 6-8 and 4-6 km, respectively. Consequently, radiation coming from atmospheric lower layers and the surface is shielded by the water vapor absorption and thus these channels are generally not affected by changes of the surface emissivity. Finally, the $190 \mathrm{GHz}$ channel has a weighting function peaking around $2 \mathrm{~km}$ where the surface emission signal is negligible and the contribution comes essentially from water vapor. Note that, however, when the water vapor content decreases this channel measures the TB below $2 \mathrm{~km}$ due to the lowering of the peak of the weighting function. In this case the surface contribution is not anymore negligible.

When searching for the right combination of PMW channels for snowfall retrieval it is crucial to first discriminate between precipitation and snow cover on the ground. A radiative transfer modeling for different surface types and atmospheric conditions was conducted by Bauer and Grody [38], including multiple scattering and depolarization by cloud droplets and precipitating droplets and ice spheres. The combination of a window channel (in their case the one at $91 \mathrm{GHz}$ ), and an atmospheric sounding channel $(183 \pm 7 \mathrm{GHz})$, led to improvements in the separation of snow cover and precipitation. Wang et al. [39] used four frequencies between 150 and $220 \mathrm{GHz}$ to derive a robust retrieval of precipitable water (PW) in the Arctic allowing for surface emissivity varying linearly with frequency. They also found that surface temperature variations introduce only a small error in the PW estimation. More in general, the use of PMW channels over land is limited to mid- and upper-tropospheric sounding channels because of the lack of adequate surface emission modeling. Weng et al. [40] simulated the global distribution of land surface emissivity for use in remote sensing in the window regions and compared results with the AMSU retrievals; the largest discrepancies occur primarily at high latitudes where the snow properties are complex and not well understood. Recently, Prigent et al. [41] have proposed a new approach based on the AMSU-A frequencies (23.8-89 GHz) to provide more dynamic emissivity estimates as a function of the local state of the atmosphere and surface. This is in fact crucial when retrieving snowfall accumulating on the ground or when the temperature changes thus determining transitions from wet to dry (or vice versa) snow cover. 
Figure 2. 26 September 2006. TBs (K) of the AMSU-B channels over Italy for a cold frontal situation. (a) $89 \mathrm{GHz}$, (b) $150 \mathrm{GHz}$, (c) $184 \mathrm{GHz}$, (d) $186 \mathrm{GHz}$ and (e) $190 \mathrm{GHz}$. Note the increase of the values at $89 \mathrm{GHz}$ over the sea and decrease over land corresponding to the cloud system, and the strong scattering at $150 \mathrm{GHz}$ due to ice hydrometeors at the cloud top.

(a)

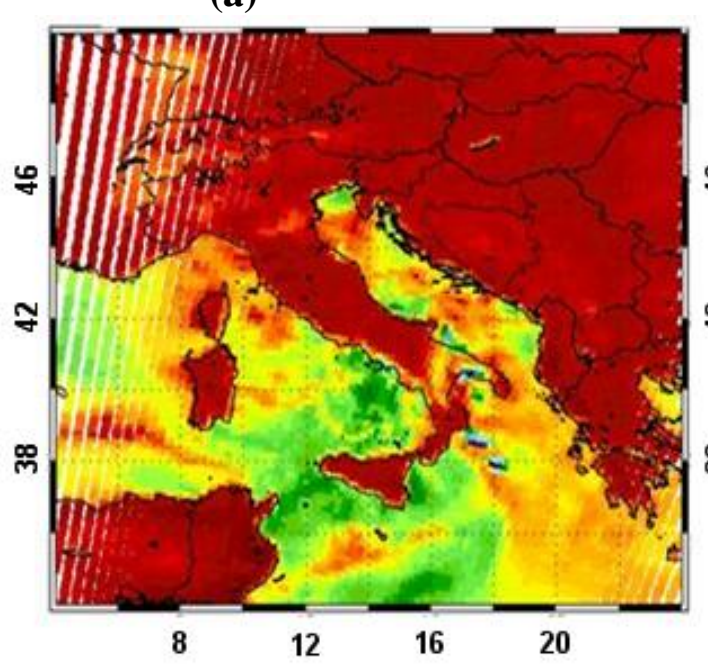

(d)

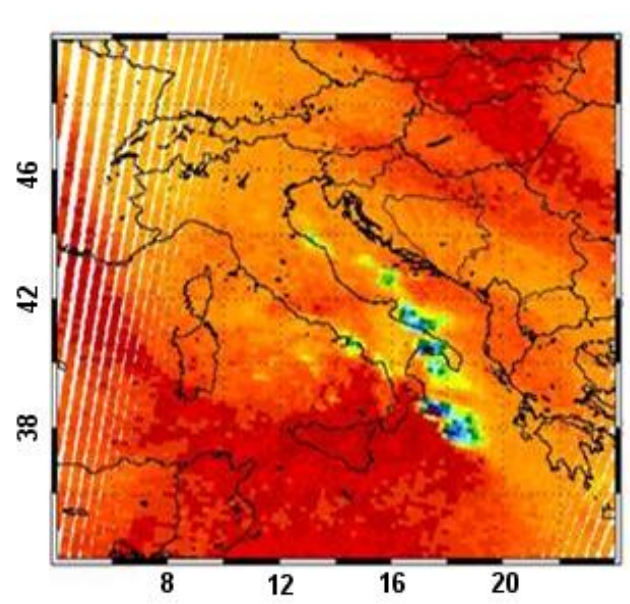

(b)

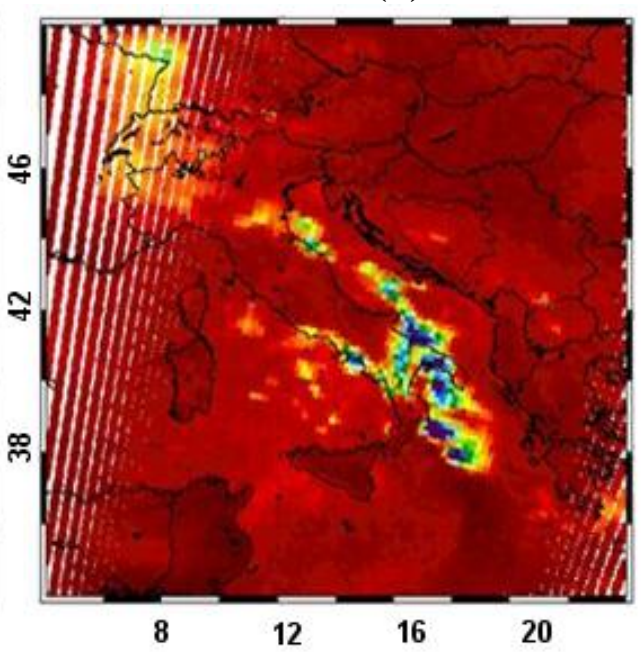

(c)

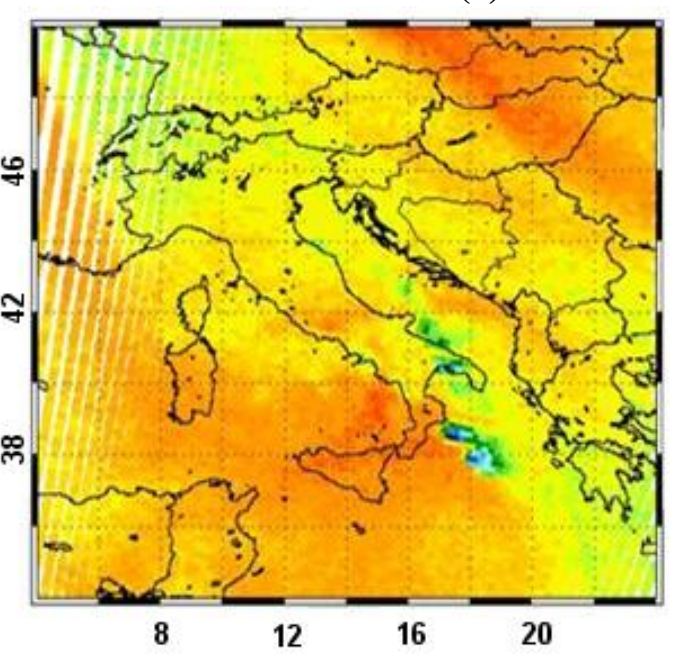

(e)

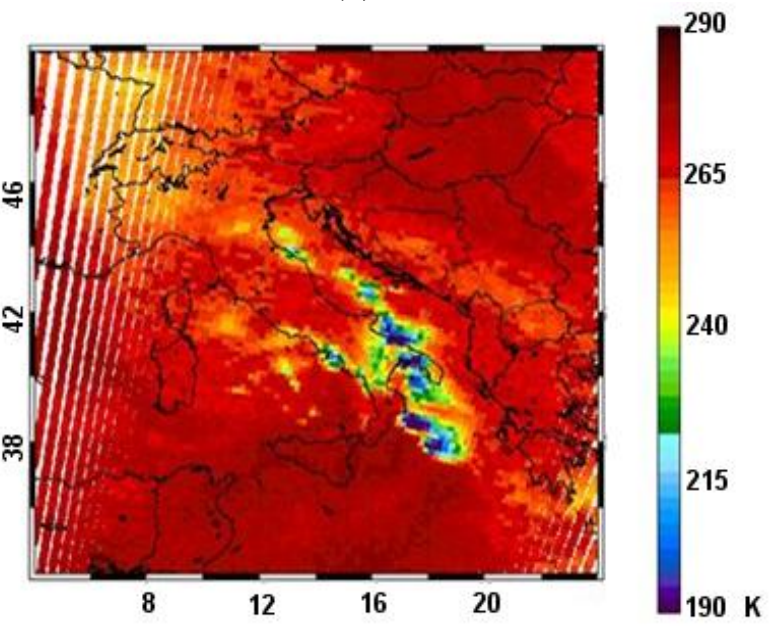




\section{Snowfall Retrieval Methods from Space}

It should be clear from the above review of remote sensing issues concerning ice clouds that designing an algorithm for snowfall detection using PMW observations from satellite presents difficulties that often exceed those of the rainfall retrieval algorithms. Note that the difficulties stemming from the scarce knowledge of the cloud vertical structure, the separation of snowfall from snow cover signals, and the ability to model scattering and emission in mixed clouds, are far from being solved. Research is ongoing and the exploitation of the current sensors for operational applications is not feasible. However, several algorithms have been proposed that provide a first approximation to the solution of the problem of snowfall intensity retrieval. In the following, a review of the algorithms available to date is presented by dividing them between two categories, those based on PMW observations and those that dwell on radar observations from space.

\subsection{Passive Microwave Methods}

The PMW snowfall intensity retrieval algorithms can be roughly divided in two categories, i.e., those based on the definition of TB thresholds and the physically based ones. Note that, however, it is quite difficult to delimit categories like "empirical" and "physical" so that the most recent algorithms all have a physical basis of some sort.

Liu and Curry [42] in 1997, used the SSM/I and the Special Sensor Microwave water vapor sounder (SSM/T2) to identify liquid and solid precipitation over the Greenland-Iceland-Norwegian Seas and devise a new snowfall retrieval algorithm. Already at this stage, the major problem of comparing with very scarce or non-existent ground truth was noted, although the snowfall algorithm showed a general agreement with shipboard snowfall frequency data. The authors also underlined the general difficulty of detecting snowfall over ice surfaces due to the scattering of falling snow that resembles that of the underlying surface. This is even truer in case of young ice because of its horizontal inhomogeneity. Katsumata et al. [43] observed snow-producing clouds over the Sea of Japan using the Airborne Microwave Radiometer (AMR), a prototype simulator of the Advanced Microwave Scanning Radiometer (AMSR). The observations, although limited below $89 \mathrm{GHz}$ by the instrument design, showed that the retrieved liquid and snow water amounts compared reasonably well with coincident radar observations. The results suggested also that the data from high-frequency microwave channels could be used to estimate the liquid water path (LWP) and snow water path (SWP) above the freezing level, especially for snow clouds. Improvements could be attained on achieving a better knowledge of the horizontal/vertical distribution of the hydrometeors.

A set of algorithms to identify precipitation and classify it according to its intensity for nowcasting applications was introduced by Bennartz et al. [44]. Since the method is designed to work over different surface types, it relies mainly on the scattering signal of precipitation sized ice particles received at high frequencies. For the calibration and validation of the method an eight-month dataset was used of combined weather radar and AMSU data obtained over the Baltic area. Results were compared for the AMSU-B channels at 89 and $150 \mathrm{GHz}$ and the high frequency channel at $150 \mathrm{GHz}$ was found to allow for a much better discrimination of different types of precipitation than the $89 \mathrm{GHz}$ 
channel. While precipitation-free areas, as well as heavily precipitating areas (intensity $>5 \mathrm{~mm} \mathrm{~h}^{-1}$ ), can be identified to a high accuracy, the intermediate classes are more ambiguous.

The group at the National Oceanic and Atmospheric Administration (NOAA) National Environmental Satellite, Data and Information Service (NESDIS) has designed a series of algorithms based on cross-track satellite radiometers (AMSR and AMSU) that aim at retrieving precipitation over sea and over land [45-47] for operational use and application in hydrology [48,49]. A snowfall detection algorithm was added by Kongoli et al. [50]. The AMSU rain rate algorithm, which imbeds a surface temperature estimate from forecast models, is first used to identify rain. When rain is not present, potential snowfall is identified when the brightness temperatures TB176 and TB180 drop below $255 \mathrm{~K}$, and the limb corrected brightness temperature at $53.6 \mathrm{GHz}$ (TB54) is above $245 \mathrm{~K}$. Removal of false alarms from potential snowfall is achieved by applying the following filters: TB176 - TB180 $\leq-20 \mathrm{~K}$ or TB150 - TB180 $\leq-40 \mathrm{~K}$ (see Figure 3). A further development of the snowfall retrieval algorithm was proposed by Meng et al. [51] using AMSU or the Microwave Humidity Sounder (MHS) data linking snowfall rate and IWP; the retrieved IWP is matched to radar data from the Next Generation Weather Radar (NEXRAD) over the conterminous United States (CONUS) and the algorithm runs operationally. The authors note that the algorithm catches basic snowfall patterns, but might miss snowfall or underestimate high snowfall rate $>0.4 \mathrm{~mm} \mathrm{~h}^{-1}$.

Figure 3. Histograms of TB54 (upper left), TB176 - TB180 (upper right) and TB150 - TB180 (lower left), and filtered scatter plot of TB176 and TB180 (lower right) from Kongoli et al. [50]. [Courtesy of the American Geophysical Union].
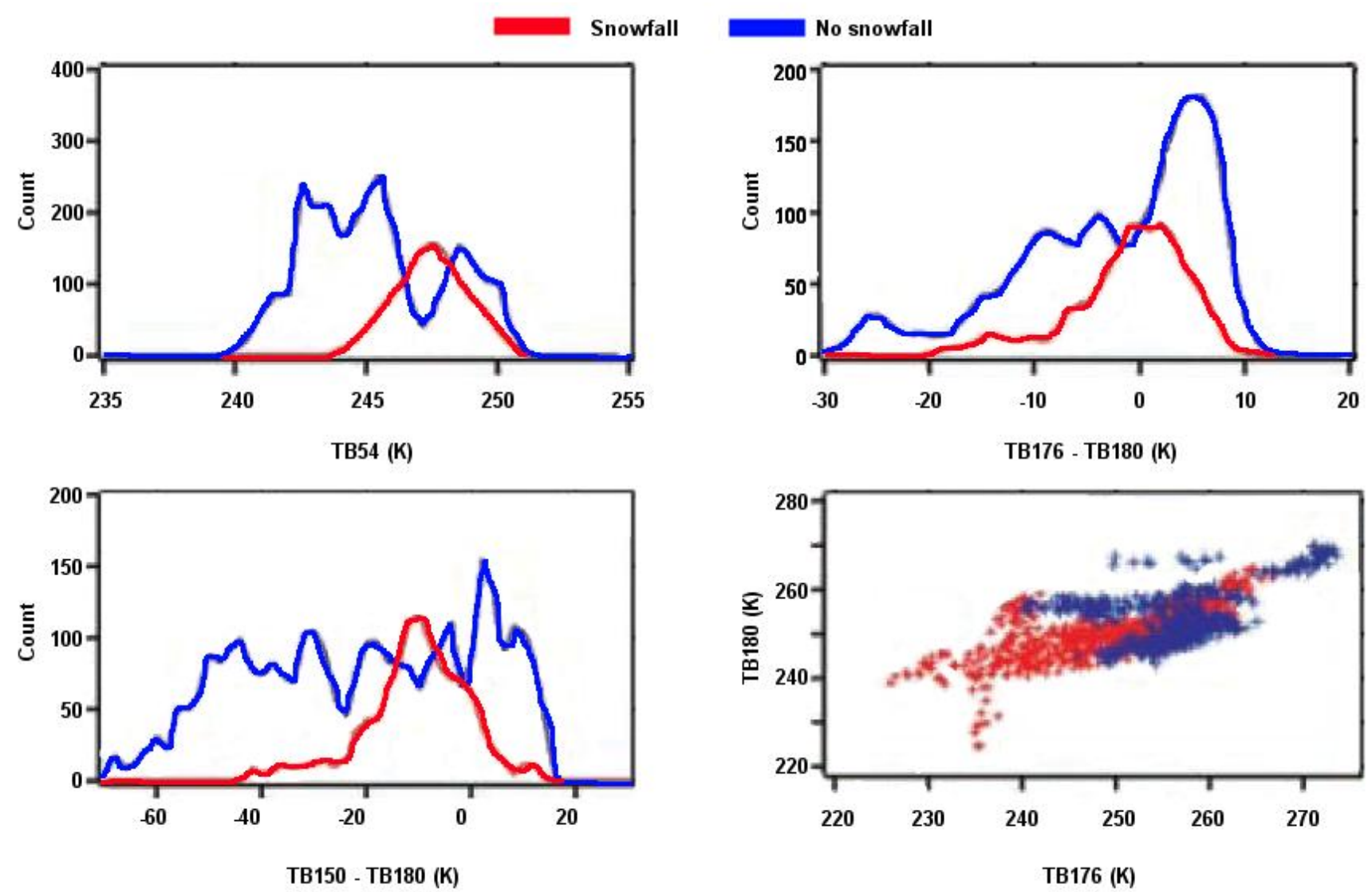
High frequency $(>100 \mathrm{GHz})$ observations from the AMSU-B were used by Skofronick-Jackson et al. [52] during the 5-6 March 2001 New England blizzard to investigate the detection of snowfall over land. The AMSU-B data are compared to NEXRAD reflectivities. The radiative effects of a snow model are compared with observations. Low altitude water vapor is shown to obscure emission from the underlying ground at high frequencies, but at high altitudes water vapor also reduces the impact of scattering by snow particles.

Because microwave TBs over snow-covered surfaces are highly variable, precipitating snow above such surfaces is difficult to observe using window channels at low frequencies ( $<100 \mathrm{GHz})$. At frequencies $\leq 37 \mathrm{GHz}$ the sensitivity to liquid hydrometeors is dominant. These problems are mitigated at high frequencies $(>100 \mathrm{GHz}$ ) where water vapor screens the surface emission, and sensitivity to frozen hydrometeors is significant. However, the scattering effect of snowfall in the atmosphere at those higher frequencies is also impacted by water vapor in the upper atmosphere. Skofronick-Jackson et al [53] have noted that the theory of scattering by randomly oriented dry snow particles at high microwave frequencies appears to be better described by regarding snow as a concatenation of "equivalent" ice spheres rather than as a sphere with the effective dielectric constant of an air-ice mixture. An equivalent sphere snow scattering model was validated against high-frequency attenuation measurements. The authors used satellite-based high-frequency observations from AMSU-B during the 5-6 March 2001 New England blizzard to retrieve snowfall over land. Vertical distributions of snow, temperature, and relative humidity profiles were derived from the Mesoscale Model (MM5) cloud model. Those data were applied and modified in a radiative transfer model that derived TBs consistent with the AMSU-B observations. The paper emphasizes the need for a dedicated set of coincident observations that include PMW as well as microphysics measurements. Field campaigns are needed to measure the high-frequency electromagnetic properties of snow along with the habits of frozen hydrometeors to yield parameters that the authors were forced to derive from disparate observations. Such measurements need to include the small as well as the large dimensions of frozen hydrometeors. The physical model was successively updated by Kim et al. [54] using five different snow particle models (Figure 4). Snow particle size distributions were assumed to vary with air temperature and to follow aircraft measurements. TBs at AMSU-B frequencies for the New England blizzard are calculated using the discrete dipole approximation (DDA) for single scattering parameters and particle size distributions. The vertical profiles of pressure, temperature, relative humidity and hydrometeors were once more provided by MM5 model simulations. These profiles were treated as the a priori database in the Bayesian retrieval algorithm. The calculated TBs associated with selected database profiles agree with AMSU-B observations to within about $\pm 5 \mathrm{~K}$ at all five frequencies. Retrieved snowfall rates compare favorably with the near-concurrent National Weather Service (NWS) radar reflectivity measurements. All of the reflectivity-precipitation rate relationships $\left(Z_{\mathrm{e}}-\mathrm{R}\right)$ fall in the range of previously established relationships for snowfall. 
Figure 4. Snowflakes models used by Kim et al. [54] for their DDA calculations in the physical model of snow retrieval: Hollow column (HC), snow aggregates composed by two cylinders (C2), three cylinders (C3), four cylinders (C4), and hexagonal plates (HP). [Courtesy of the American Geophysical Union]

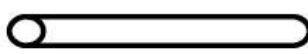

$\mathrm{HC}$

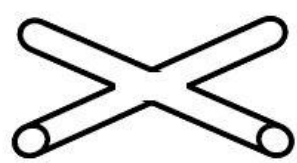

C2

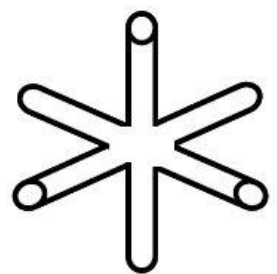

C3

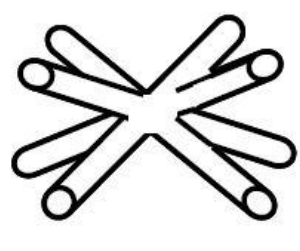

C4

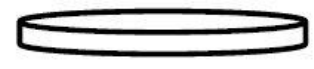

HP

A snowfall and snow cover retrieval algorithm [55] is currently being developed as a module of the precipitation retrieval algorithm Water Strong Lines at $183 \mathrm{GHz}$ (183-WSL) of Laviola and Levizzani [56-58]. The module is based on TB differences of AMSU-B calibrated against NEXRAD data. The following differences were used: TB89 - TB150, TB150 - TB190, and TB190 - TB186. False snowfall signal are discriminated using the TB186 - TB184. The TB184 signal was found useful to identify the convection areas deeper than $8 \mathrm{~km}$. Figure 5 shows an application of the module to a blizzard on 9-10 March, 2010 over Italy: Note the separation between convective and stratiform rain, wet and dry snow cover, snowfall, water clouds, and water vapor.

Figure 5. 9-10 March 2010. Precipitation and snow cover maps from the 183-WSL algorithm [58] for a snow blizzard over Italy.
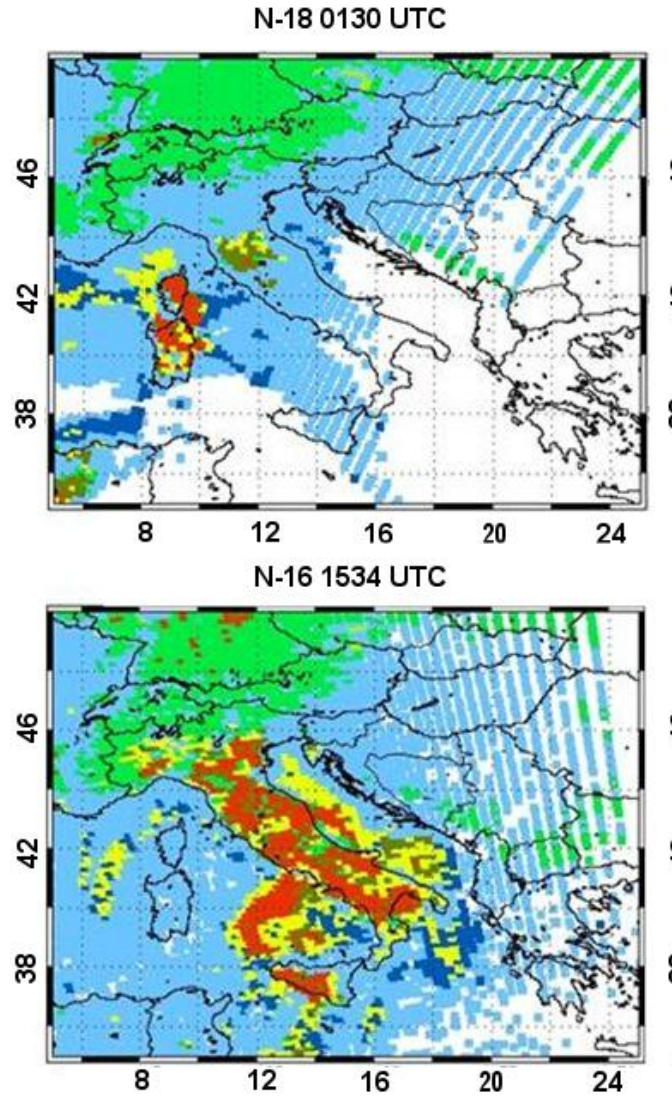
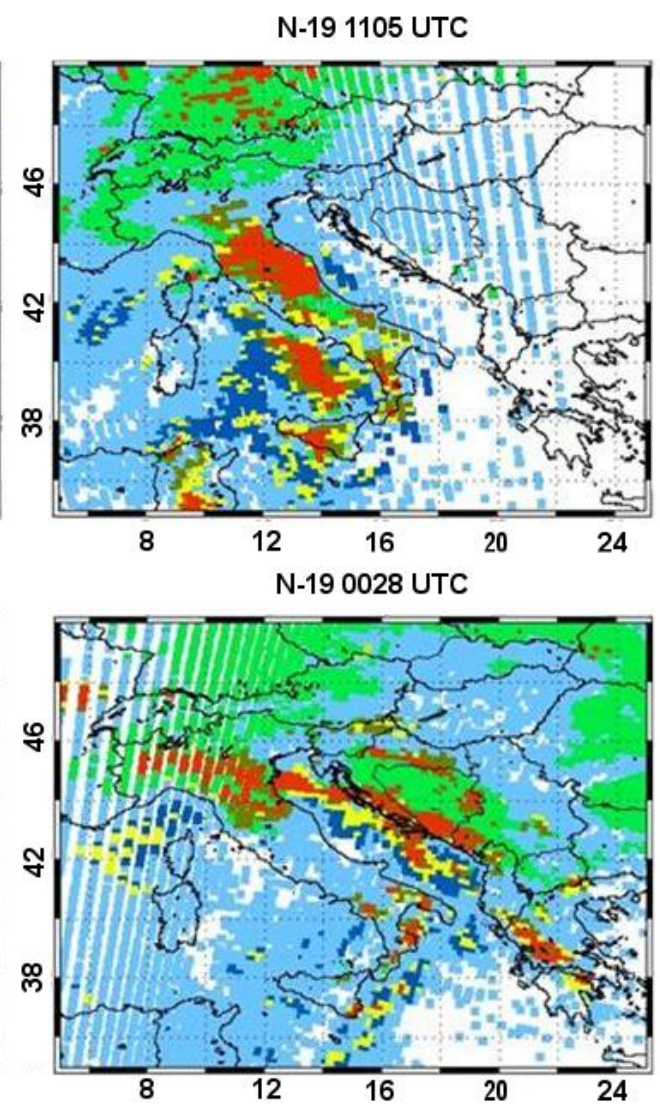

Water vapor

Water clouds (droplets) Snowfall

Wet snow cover

Dry snow cover

Stratiform rain

Convective rain 
A Bayesian technique was proposed by Noh et al. [59] for snowfall retrieval over land using high frequency AMSU data. Satellite and surface-based radar data and in situ aircraft measurements are used to build the a priori database consisting of snowfall profiles and corresponding TBs. The retrieval algorithm is applied to snowfall cases that occurred over the Great Lakes region, and the results are compared with the surface radar data and daily snowfall data collected from NWS stations.

All the above described algorithms have limitations in snowfall detection and snowfall intensity retrieval because of the inadequate knowledge of the ice cloud structure. In situ observations by means of aircraft penetrations are not always possible and do not ensure a global coverage and sampling of all possible snow forming clouds. This is the main reason why radar from space appears as the only viable alternative to map ice cloud structure.

\subsection{Radar Methods}

The launch of CloudSat [60] in April 2006 brought a 94 GHz cloud profiling radar (CPR) in space for the first time. The CPR does not scan and observes a strip of $\sim 1.5 \mathrm{~km}$ on the surface for each overpass limiting the ability of obtaining snowfall distribution from the CPR alone. However, the CPR allows for an unprecedented survey of the horizontal and vertical distribution of snowfall on a global scale. An example of CloudSat overpassing a snow storm in Northern China is shown in Figure 6.

Liu [61] devised a method for the snowfall retrieval based on: (1) A snow-rain threshold based on surface air temperature; and (2) a radar reflectivity-snowfall rate relation $\left(Z_{e}-S\right)$. The former is based on multiyear land station and shipboard weather reports, and the latter is based on backscatter computations of non spherical ice particles and in situ measured particle size distributions. The first step dwells on the work of Matrosov [62] who developed a $Z_{e}-S$ relation for $94 \mathrm{GHz}$ radar by assuming that the snowflakes are oblate spheroids with an aspect ratio of 0.6 and a preferable horizontal orientation. To derive a new $\mathrm{Ze}-\mathrm{S}$ relation based on ice particle shapes that more closely resemble natural snowflakes, Liu [61] used three particle types: Rosettes (with three, four, and six bullets); sectors; and dendrites to represent snowflakes. A first climatology of snowfall was derived although very preliminary, due to the difficulties in obtaining ground truth data.

A retrieval of ice cloud microphysics was developed by Austin et al. [63] for use with millimeter-wave radar from ground-, air-, or space-based sensors with special emphasis on CloudSat. The method is developed from an earlier retrieval [64,65] that used measurements of the radar reflectivity factor together with a priori information about the likely cloud targets. The new retrieval includes temperature information to assist in determining the correct region of state space, particularly for those size distribution parameters that are less constrained by the radar measurements. Comparisons involving simulated radar data based on a cloud probe database showed generally good performance, with IWC biases estimated to be less than 40\%. Comparisons to IWC and IWP estimates by other instruments are mixed. When the comparison is restricted to different retrieval approaches using the same CloudSat radar measurements, the new retrievals generally agree with alternative IWC retrievals for IWC $<1000 \mathrm{mg} \mathrm{m}^{-3}$ at altitudes below $12 \mathrm{~km}$, but differ at higher ice contents and altitudes, either exceeding other retrievals or falling within a spread of retrieval values. Validation continues to be a research topic of utmost importance. 
Figure 6. 12 November 20091800 UTC. Early season heavy snow storm classified as one of the worst snow storms in decades to hit northern China with over 32 casualties, thousands of acres of crops destroyed, and 15000 buildings collapsed. The CloudSat flight path is shown by the blue line on the IR emissivity image (top). The sensitivity of the CloudSat CPR (bottom) can be used to estimate the vertical and horizontal snowfall distributions from the shallow snow-bearing clouds. Note that the CPR image is a qualitative display of the radar reflectivity (dBZ) increasing from a minimum/blue to a maximum/white. [Courtesy of the Department of Atmospheric Sciences, Colorado State University and the CloudSat project, http://cloudsat.atmos.colostate.edu/].
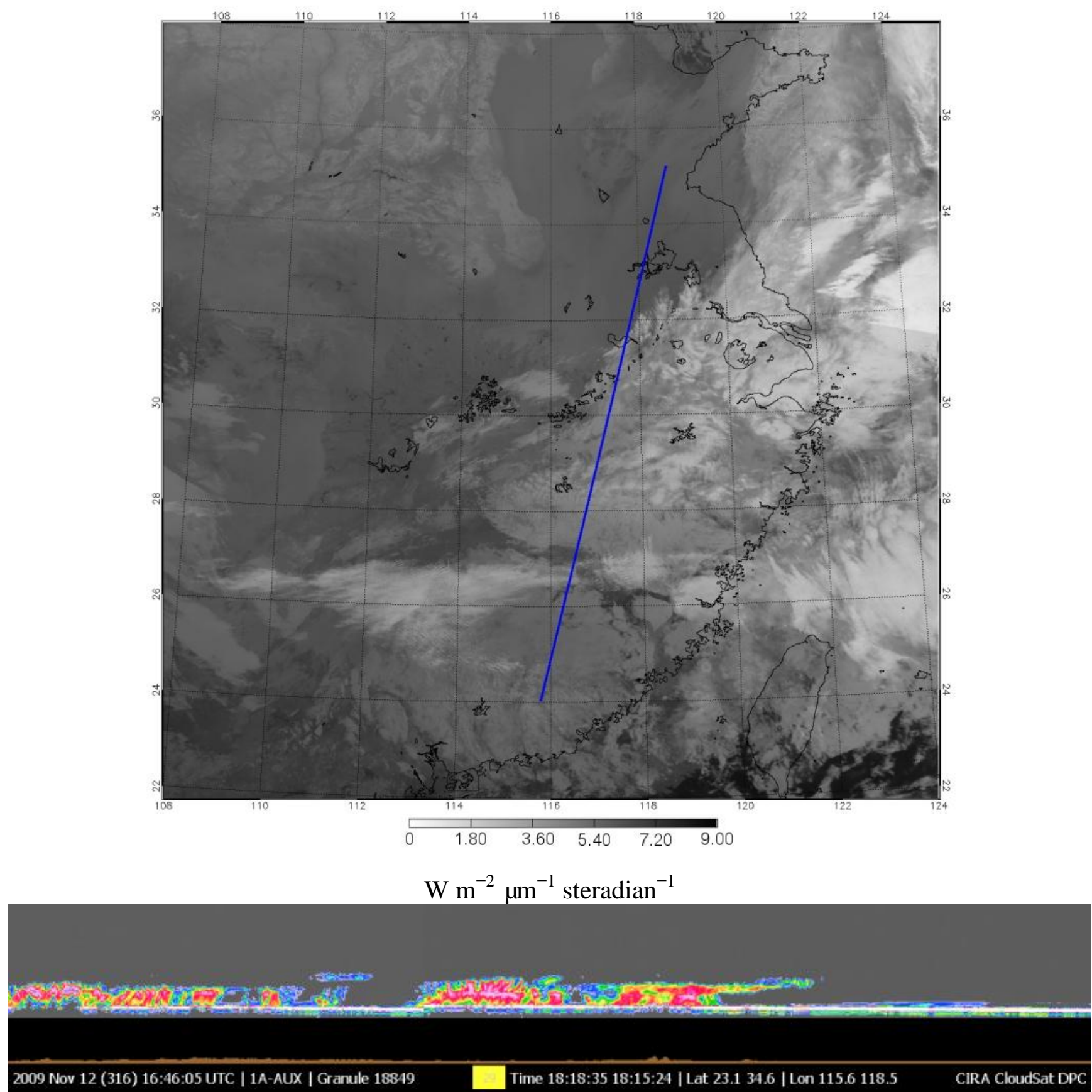

Another approach consists of using combined radar-radiometer methods to retrieve snowfall. Johnson et al. [66] have proposed an algorithm that retrieves a 1-D vertical distribution of precipitation 
rate, particle size, particle density, and cloud liquid water content using aircraft or satellite-based co-located dual-wavelength radar and passive microwave radiometer observations. The observations were those of the 2003 Wakasa Bay field experiment over the Sea of Japan where high-resolution observations of snowfall using aircraft-based instruments were taken. The dual-frequency Precipitation Doppler Radar (PR-2) operated at 13.4 and $35.6 \mathrm{GHz}$, while the co-located MIR radiometer observed cross-track TBs at 89, 150, 184, 186, 190, 220 and $340 \mathrm{GHz}$. The retrieval method consists of: (1) The radar dual-wavelength ratio (DWR) method; and (2) the subsequent constraint by PMW TB comparisons. The DWR method is ill-posed due to uncertainties in the particle composition and cloud LWCs. The authors use as an additional constraint, the forward model to simulate the top-of-the-atmosphere PMW TBs for the candidate retrieved profiles, obtained using the DWR method. These simulated TBs are compared to the observed TBs. Those profiles having the smallest TB root mean square error (RMSE) difference are selected as the optimal retrieved profiles. However, the problem remains ill-posed and additional observations are required to constrain the retrievals. The techniques are being developed with an eye toward the upcoming Global Precipitation Measurement (GPM) mission.

Another method was developed using data from the same experiment over the Sea of Japan by Grecu and Olson [67]. The authors proposed an algorithm for retrieving snow over oceans from combined cloud radar and millimeter-wave radiometer observations. The electromagnetic scattering properties of snowflakes are determined based on calculations using the DDA approach of Draine and Flatau [68] and the generalized multiparticle Mie (GMM) approach of Xu and Gustafson [69]. Synthetic data from a cloud resolving model (CRM) were used as a test of the algorithm previous to application to data from the Wakasa Bay experiment. Snow estimates are consistent with both the cloud radar and radiometer observations. Moreover, the estimates are, overall, similar (although with systematic differences in the vertical structure) to estimates from the same algorithm applied to combined Ku-band and millimeter-wave radiometer observations. Finally, the authors found that the snow estimates are sensitive to assumptions made on the snow density, with a $12.5 \%$ bias resulting from a factor-of-2 error in the assumed snow density.

\section{Future Research}

Future research must tackle the weakest points in the above research efforts, i.e., the inadequate representation of the cloud vertical structure in the radiometer- and radar-based models of snow retrieval. The field is young and, only recently, a ground-satellite integrated radar observing system was established with the launch of CloudSat.

First of all, further studies need to address the quality of snow detection from CloudSat. Battaglia et al. [70] have already addressed the issue of the presence of multiple scattering whose consideration in the rainfall and snowfall retrieval can give substance of the otherwise positive biases. More recently, Matrosov and Battaglia [71] have carried out initial quantitative estimates of multiple scattering "dry" snow. They show that these effects become significant (approximately $>1 \mathrm{~dB}$ ) when snowfall radar reflectivity factors are > 10-15 dBZ. Reflectivity enhancement due to multiple scattering can reach 4-5 dB in heavier stratiform snowfalls. Multiple scattering effects counteract signal attenuation, so that the observed CloudSat reflectivity factors in snowfall could be relatively 
close to the values that would be observed in the case of single scattering and the absence of attenuation. Recently, Kulie and Bennartz [72] have used backscatter cross sections of various nonspherical and spherical ice particle models to estimate the snowfall rate for dry snow.

Another example on how the studies need to focus on the physics of the snow-producing clouds is the Canadian CloudSat Validation Project (C3VP; http://c3vp.org/) that makes use of the Environment Canada (EC) ground radar network. Hudak et al. [73] have verified the ability of CloudSat to detect precipitation in cold season cloud systems over Ontario. They identified complicating factors in the time mismatch between ground and space radar scans, the differences in sensitivity, and the changes to the geometry of cross section with range from the ground radar, $\mathrm{W}$ band radar attenuation, and the effect of ground clutter. In about $14 \%$ of the precipitation profiles considered by the authors, time mismatches were diagnosed. When these cases were removed, the skill scores of the CloudSat precipitation occurrence product were excellent. The most frequent cause of a false detection was an incorrect precipitation threshold in the algorithm. The most frequent cause of a miss in detection was ground clutter removal of valid echoes by the algorithm. The work is being continued as more CloudSat snowfall profiles become available using coincident CPR (94 GHz W-band), EC radar (5 GHz C-band) and AMSR-E/AMSU-B/MHS sounders (10-183 GHz) [74] observations. The observed versus simulated snow profiles are directly compared in the radar/radiometer measurement space thus avoiding the Z-S relations and similar potential error sources. This should give an idea of the physics of the problem and suggest possible solutions.

On this advanced research topic is the work of Wang et al. [75,76] whose intent is to construct an a priori database for the Bayesian-type satellite PMW snowfall retrieval algorithms for GPM using ground validation field campaign data in conjunction with satellite snowfall observations and CRM simulations. The authors use the C3VP field campaign data along with MHS observations and CRM simulation using the Weather Research and Forecast (WRF)/Goddard microphysics scheme; the radiative transfer simulations assumed spherical snow particles. CloudSat and MHS snow size distribution estimation and reflectivity and TB simulations were for non-spherical particles. The authors find that the water vapor sounding channels (183 and $190 \mathrm{GHz}$ ) simulations are fairly consistent with satellite observations while the window channels are sensitive to surface emissivity. This latter is a key point to be incorporated using either estimations before/after a clear day or an average over a certain time period.

Todini et al. [77] discussed a snowfall detection approach for high-latitude regions based on a combination of passive sensors to discriminate between snowing and non-snowing areas. They used AMSU-A and B PMW data together with observations from the Moderate Resolution Imaging Spectroradiometer (MODIS) [78] on the Aqua satellite and CPR data from CloudSat. The multi-sensor approach was first based on a logistic distribution to represent the probability of snowfall given the predictors and then using a Bayesian technique. A comparison was carried out with retrievals from the technique of the group at Massachusetts Institute of Technology [79-82] showing that both proposed methods discriminate snow and no-snow conditions in the polar regions with an overall reduction of the false alarms by at least $30 \%$ while considerably increasing the probability of detection. This would confirm the potential of using multisensor, multispectral approaches. 
From the point of view of space missions, attention should be given to reach a better coverage. The GPM mission is scheduled for launch in 2013 and its core satellite will host a PMW radiometer of the last generation and a dual frequency radar. The aim is to ensure a 3-hourly global coverage of precipitation intensity measurements. However, the mission is not devoted to snowfall and high latitudes so that above 60 degrees existing missions and newly conceived ones will need to contribute input. One of such missions has recently been proposed by Marzano et al. [83]. Note that a combined effort by all participating countries to GPM is needed to ensure a complete coverage; this is not secured to date by the plans of the various space agencies that seem to pursue their own launch schedule without a real coordination on the subject of the water cycle.

Considering the science and technology of active and passive snowfall sensing from space, there are a few points that need to be tackled to make any real progress. First, major improvements can be expected from advancing the radar technology. Building a dual-wavelength $\mathrm{W}$ - and Ka-band radar with minimum detection around $-25 \mathrm{dBZ}$ together with Doppler functionality would be a substantial leap forward. This would, for example, allow resolving terminal velocities around $0.2 \mathrm{~m} \mathrm{~s}^{-1}$ for the separation of rainfall from snowfall (e.g., aggregates and single dendritic crystals) thus influencing first the detection capabilities and then the quantitative retrieval.

In the area of PMW remote sensing, there are still considerable limitations stemming from the relatively scarce understanding we have of mixed phase clouds. Characterizing the liquid water content and distribution in snow-producing clouds is crucial for a correct interpretation of PMW signals. At present, often at high PMW frequencies snowing clouds appear warmer than the clear sky instead of cooler due to the presence of liquid water. Field experiments are thus needed in such conditions to try to solve the problem.

Finally, from the cloud-physics and radiative side two are the major problems yet to be faced. On one side, ice crystal aggregates scatter more than single ice crystals. The scattering properties of these aggregates are not quite known to date and should be studied more. On the other side, only few measurements of the size distributions of hydrometeors in snowstorms are available (e.g., [84]) or understood to the point that drop size distributions are. Ice particle density [85], dimensions and aggregation modes are also open problems and need more attention. There are not many in situ and ground observations available and this poses problems for radiative transfer simulations and retrievals.

In summary, research must now concentrate on: (1) Advancing the radar technologies; (2) organizing field campaigns; and (3) doing radiative transfer simulations that will allow for answering the open question on how well we can detect snowfall from PMW and radar from space for operational applications.

\section{Acknowledgements}

The work was supported by EUMETSAT within the Satellite Application Facility on Support to Operational Hydrology and Water Management (H-SAF). Essential support was provided by the Italian Civil Protection Agency within the CNR-DPC Agreement and by the Italian Space Agency (ASI) under the project "Protezione Civile dalle Alluvioni: Il Nowcasting". Two anonymous reviewers deserve recognition for their very helpful comments that considerably helped improving the original manuscript. 


\section{References and Notes}

1. Worley, S.J.; Woodruf, S.D.; Reynolds, R.W.; Lubker, S.J.; Lott, N. ICOADS Release 2.1 data and products. Int. J. Climatol. 2005, 25, 823-842.

2. Doesken, N.J.; Judson, A. The Snow Booklet: A Guide to the Science, Climatology and Measurements of Snow in the United States, 2nd ed.; Colorado State University: Fort Collins, CO, USA, 1996; p. 85.

3. ESA. EGPM-European Contribution to Global Precipitation Measurement; ESA SP-1279(5); ESA: Noordwijk, The Netherlands, 2004; p. 60.

4. Kidd, C.; Levizzani, V.; Bauer, P. A review of satellite meteorology and climatology at the start of the twenty-first century. Progr. Phys. Geog. 2009, 33, 474-489.

5. Kidd, C.; Levizzani, V.; Turk, F.J.; Ferraro, R.R. Satellite precipitation measurements for water resource monitoring. J. Amer. Water Resour. Assoc. 2009, 45, 567-579.

6. Levizzani, V.; Bauer, P.; Turk, F.J. Measuring Precipitation from Space: EURAINSAT and the Future; Springer: Dordrecht, The Netherlands, 2007; p. 722.

7. Michaelides, S.; Levizzani, V.; Anagnostou, E.N.; Bauer, P.; Kasparis, T.; Lane, J.E. Precipitation: Measurement, remote sensing, climatology and modeling. Atmos. Res. 2009, 94, 512-533.

8. Justo, J.E.; Weickmann, K.K. Types of snowfall. Bull. Amer. Meteor. Soc. 1973, 54, 1148-1162.

9. Magono, C.; Lee, C.W. Meteorological classification of natural ice crystals. J. Faculty Sci. Hokkaido Univ. Ser. VII 1966, 2, 321-335.

10. Liu, G.; Curry, J.A. An investigation of the relationship between emission and scattering signals in SSM/I data. J. Atmos. Sci. 1998, 55, 1628-1643.

11. Hobbs, P.V.; Chang, S.; Locatelli, J.D. The dimensions and aggregation of ice crystals in natural clouds. J. Geophys. Res. 1974, 79, 2199-2206.

12. Gunn, K.L.S.; Marshall, J.S. The distribution with size of aggregate snowflakes. J. Meteorol. 1958, 15, 452-461.

13. Auer, A.H.; Veal, D.L.; Marwitz, J.D. Observations of ice crystal and ice nuclei concentrations in stable cap clouds. J. Atmos. Sci. 1969, 26, 1342-1343.

14. Mossop, S.C. Concentrations of ice crystals in clouds. Bull. Amer. Meteor. Soc. 1970, 51, 474-479.

15. Mätzler, C.; Rosenkranz, P.W.; Cermak, J. Microwave absorption of supercooled clouds and implications for the dielectric properties of water. J. Geophys. Res. 2010, 115, D23208, doi:23210.21029/22010JD014283.

16. Kneifel, S.; Löhnert, U.; Battaglia, A.; Crewell, S.; Siebler, D. Snow scattering signals in ground-based passive microwave radiometer measurements. J. Geophys. Res. 2010, 115, D16214, doi:16210.11029/12010JD013856.

17. Field, P.R.; Wood, R.; Brown, P.R.A.; Kaye, P.H.; Hirst, E.; Greenaway, R.; Smith, J.A. Ice particle interarrival times measured with a fast FSSP. J. Atmos. Oceanic Technol. 2003, 20, 249-261.

18. Field, P.R.; Heymsfield, A.J.; Bansemer, A. Shattering and particle interarrival times measured by optical array probes in ice clouds. J. Atmos. Oceanic Technol. 2006, 23, 1357-1371.

19. Heymsfield, A.J.; Field, P.; Bansemer, A. Exponential size distributions for snow. J. Atmos. Sci. 2008, 65, 4017-4031. 
20. Korolev, A.V.; Isaac, G.A.; Mazin, I.P.; Barker, H.W. Microphysical properties of continental clouds from in situ measurements. Quart. J. Roy. Meteor. Soc. 2001, 127, 2117-2151.

21. Gultepe, I.; Isaac, G.A.; Cober, S.G. Ice crystals number concentration versus temperature for climate studies. Int. J. Climatol. 2001, 21, 1281-1302.

22. Korolev, A.V.; Isaac, G.A.; Cober, S.G.; Strapp, J.W.; Hallett, J. Microphysical characterization of mixed-phase clouds. Quart. J. Roy. Meteor. Soc. 2003, 129, 39-65.

23. Wilheit, T.T.; Chang, A.T.C.; King, J.L.; Rodgers, E.B.; Nieman, R.A.; Krupp, B.M.; Milman, A.S.; Stratigos, J.S.; Siddalingaiah, H. Microwave radiometric observations near 19.35, 92 and 183 GHz of precipitation in Tropical Storm Cora. J. Appl. Meteor. 1982, 21, 1137-1145.

24. Bennartz, R.; Petty, G.W. The sensitivity of microwave remote sensing observations of precipitation to ice particle size distributions. J. Appl. Meteor. 2001, 40, 345-364.

25. Evans, K.F.; Stephens, G.L. Microwave radiative transfer through clouds composed of realistically shaped ice crystals. Part I: Single scattering properties. J. Atmos. Sci. 1995, 52, 2041-2057.

26. Evans, K.F.; Stephens, G.L. Microwave radiative transfer through clouds composed of realistically shaped ice crystals. Part II: Remote sensing of ice clouds. J. Atmos. Sci. 1995, 52, 2058-2072.

27. Liu, G. Approximation of single scattering properties of ice and snow particles for high microwave frequencies. J. Atmos. Sci. 2004, 61, 2441-2456.

28. Doherty, A.M.; Sreerekha, T.R.; O’Keeffe, U.M.; English, S.J. Ice hydrometeor microphysical assumptions in radiative transfer models at AMSU-B frequencies. Quart. J. Roy. Meteor. Soc. 2007, 133, 1205-1212.

29. Bennartz, R.; Bauer, P. Sensitivity of microwave radiances at $85-183 \mathrm{GHz}$ to precipitating ice particles. Radio Sci. 2003, 38, 8075, doi:8010.1029/2002RS002626.

30. Hong, G.; Heygster, G.; Miao, J.; Kunzi, K. Sensitivity of microwave brightness temperatures to hydrometeors in a tropical deep convective cloud system at 89-190 GHz. Radio Sci. 2005, 40, RS4003, doi:4010.1029/2004RS003129.

31. Weng, F.; Grody, N.C. Retrieval of ice cloud parameters using a microwave imaging radiometer. J. Atmos. Sci. 2000, 57, 1069-1081.

32. Saunders, R.W.; Hewison, T.J.; Stringer, S.J.; Atkinson, N.C. The radiometric characterization of AMSU-B. IEEE Trans. Microw. Theory Tech. 1995, 43, 760-771.

33. Kakar, R.K. Retrieval of clear sky moisture profiles using the $183 \mathrm{GHz}$ water vapor line. J. Clim. Appl. Meteorol. 1983, 22, 1282-1289.

34. Wilheit, T.T. An algorithm for retrieving water vapor profiles in clear and cloudy atmospheres from $183 \mathrm{GHz}$ radiometric measurements: Simulation studies. J. Appl. Meteor. 1990, 29, 508-515.

35. Muller, B.M.; Fuelberg, H.E.; Xiang, X. Simulations of the effects of water vapor, cloud liquid water, and ice on AMSU moisture channel brightness temperatures. J. Appl. Meteor. 1994, 33, 1133-1154.

36. Greenwald, T.J.; Christopher, S.A. Effect of cold clouds on satellite measurements near 183 GHz. J. Geophys. Res. 2002, 107, D134170, doi:134110.131029/132000JD000258. 
37. Karbou, F.; Aires, F.; Prigent, C.; Eymard, L. Potential of Advanced Microwave Sounding Unit-A (AMSU-A) and AMSU-B measurements for atmospheric temperature and humidity profiling over land. IEEE Trans. Geosci. Remote Sens. 2005, 110, D07109, doi:07110.01029/02004JD005318.

38. Bauer, P.; Grody, N.C. The potential of combining SSM/I and SSM/T2 measurements to improve the identification of snowcover and precipitation. IEEE Geosci. Remote Sens. Lett. 1995, 33, 252-261.

39. Wang, J.R.; Racette, P.E.; Triesky, M.E. Retrieval of precipitable water vapor by the millimeter-wave imaging radiometer in the Arctic region during FIRE-ACE. IEEE Geosci. Remote Sens. Lett. 2001, 39, 595-605.

40. Weng, F.; Yan, B.; Grody, N.C. A microwave land emissivity model. J. Geophys. Res. 2001, 106, 20115-20123.

41. Prigent, C.; Chevallier, F.; Karbou, F.; Bauer, P.; Kelly, G. AMSU-A land surface emissivity estimation for numerical weather prediction assimilation schemes. J. Appl. Meteor. 2005, 44, 416-426.

42. Liu, G.; Curry, J.A. Precipitation characteristics in Greenland-Iceland-Norwegian Seas determined by using satellite microwave data. J. Geophys. Res. 1997, 102, 13987-13997.

43. Katsumata, M.; Uyeda, H.; Iwanami, K.; Liu, G. The response of 36- and 89-GHz microwave channels to convective snow clouds over ocean: Observation and modeling. J. Appl. Meteor. 2000, 39, 2322-2335.

44. Bennartz, R.; Thoss, A.; Dybbroe, A.; Michelson, D. Precipitation analysis using the Advanced Microwave Sounding Unit in support of nowcasting applications. Meteor. Appl. 2002, 9, 177-189.

45. Ferraro, R.R.; Weng, F.; Grody, N.C.; Zhao, L. Precipitation characteristics over land from the NOAA-15 AMSU sensor. Geophys. Res. Lett. 2000, 27, 2669-2672.

46. Ferraro, R.R.; McCollum, J.R. Rainfall over Land from the AMSR-E. In Proceedings of 2003 IEEE International Geoscience and Remote Sensing Symposium, Toulouse, France, July 21-25, 2003; pp. 669-671.

47. Weng, F.; Zhao, L.; Ferraro, R.R.; Poe, G.; Li, X.; Grody, N.C. Advanced microwave sounding unit cloud and precipitation algorithms. Radio Sci. 2003, 38, 8068, doi:10.1029/2002RS002679.

48. Grody, N.; Weng, F.; Ferraro, R. Application of AMSU for obtaining hydrological parameters. In Microwave Radiometry Remote Sensing of the Earth's Surface and Atmosphere; Pampaloni, P., Paloscia, S., Eds.; VSP BV: Zeist, The Netherlands, 2000; pp. 339-352.

49. Ferraro, R.R.; Weng, F.; Grody, N.C.; Zhao, L.; Meng, H.; Kongoli, C.; Pellegrino, P.; Qiu, S.; Dean, C. NOAA operational hydrological products derived from the Advanced Microwave Sounding Unit. IEEE Trans. Geosci. Remote Sens. 2005, 43, 1036-1049.

50. Kongoli, C.; Pellegrino, P.; Ferraro, R.R.; Grody, N.C.; Meng, H. A new snowfall detection algorithm over land using measurements from the Advanced Microwave Sounding Unit (AMSU). Geophys. Res. Lett. 2003, 30,doi:10.1029/2003GL017177. 
51. Meng, H.; Ferraro, R.R.; Yan, B. Snowfall rate retrieval using AMSU/MHS passive microwave data. In Proceedings of Joint 2007 EUMETSAT Meteorological Satellite Conference and the 15th Satellite Meteorology \& Oceanography Conference of the American Meteorological Society, Amsterdam, The Netherlands, September 24-28, 2007; Available online: http://www.eumetsat.int/Home/Main/Publications/Conference_and_Workshop_Proceedings/grou ps/cps/documents/document/pdf_conf_p50_s10_13_meng_p.pdf (accessed on 10 January 2011).

52. Skofronick-Jackson, G.M.; Weinman, J.A.; Chang, D.-E. Observation of snowfall over land by microwave radiometry from space. In Proceedings of 2002 IEEE International Geoscience and Remote Sensing Symposium, Toronto, ON, Canada, June 24-28, 2002; pp. 1866-1868.

53. Skofronick-Jackson, G.M.; Kim, M.-J.; Weinman, J.A.; Chang, D.-E. A physical model to determine snowfall over land by microwave radiometry. IEEE Trans. Geosci. Remote Sens. 2004, 42, 1047-1058.

54. Kim, M.-J.; Weinman, J.A.; Olson, W.S.; Chang, D.-E.; Skofronick-Jackson, G.; Wang, J.R. A physical model to estimate snowfall over land using AMSU-B observations. J. Geophys. Res. 2008, 113, D09201, doi:09210.01029/02007JD008589.

55. D'Aurizio, S. Sviluppo di un algoritmo per la stima delal precipitazione nevosa nelle microonde ad alta frequenza da satellite. M.Sc. Thesis, Department of Physics, University of Bologna, Bologna, Italy, 2010; p. 71.

56. Laviola, S.; Levizzani, V. Rain retrieval using the $183 \mathrm{GHz}$ absorption lines. In Proceedings of 2008 Microwave Radiometry and Remote Sensing of the Environment, Firenze, Italy, March 11-14, 2008; doi:10.1109/MICRAD.2008.4579505.

57. Laviola, S.; Levizzani, V. Observing precipitation by means of water vapor absorption lines: A first check of the retrieval capabilities of the 183-WSL rain retrieval method. Italian J. Remote Sens. 2009, 41, 39-49.

58. Laviola, S.; Levizzani, V. The 183-WSL fast rain rate retrieval algorithm. Part I: Retrieval design. Atmos. Res. 2011, doi:10.1016/j.atmosres.2010.1011.1013.

59. Noh, Y.-J.; Liu, G.; Jones, A.S.; Haar, T.H.V. Toward snowfall retrieval over land by combining satellite and in situ measurements. J. Geophys. Res. 2009, 114, D24205, doi:24210.21029/22009JD012307.

60. Stephens, G.L.; Vane, D.G.; Boain, R.J.; Mace, G.G.; Sassen, K.; Wang, Z.; Illingworth, A.J.; O’Connor, E.J.; Rossow, W.B.; Durden, S.L.; Miller, S.D.; Austin, R.T.; Benedetti, A.; Mitrescu, C.; The CloudSat Science Team The CloudSat mission and the A-Train: A new dimension of space-based observations of clouds and precipitation. Bull. Amer. Meteor. Soc. 2002, 83, 1771-1790.

61. Liu, G. Deriving snow cloud characteristics from CloudSat observations. J. Geophys. Res. 2008, 113, D00A09, doi:10.1029/2007JD009766.

62. Matrosov, S.Y. Modeling backscatter properties of snowfall at millimeter wavelengths. J. Atmos. Sci. 2007, 64, 1727-1736.

63. Austin, R.T.; Heymsfield, A.J.; Stephens, G.L. Retrieval of ice cloud microphysical parameters using the CloudSat millimeter-wave radar and temperature. J. Geophys. Res. 2009, 114, D00A23, doi:10.1029/2008JD010049. 
64. Austin, R.T.; Stephens, G.L. Retrieval of stratus cloud microphysical parameters using millimeter-wave radar and visible optical depth in preparation for CloudSat. 1. Algorithm formulation. J. Geophys. Res. 2001, 106, 28233-28242.

65. Benedetti, A.; Stephens, G.L.; Haynes, J.M. Ice cloud microphysics retrievals from millimeter radar and visible optical depth using an estimation theory approach. J. Geophys. Res. 2003, 108, D11, 4335, doi:4310.1029/2002JD002693.

66. Johnson, B.T.; Skofronick-Jackson, G.M.; Petty, G.W. Combined passive and active microwave retrieval of falling snow during the 2003 Wakasa Bay field experiment. In Proceedings of 2008 Microwave Radiometry and Remote Sensing of the Environment, Firenze, Italy, March 11-14, 2008; doi:10.1109/MICRAD.2008.4579498.

67. Grecu, M.; Olson, W.S. Precipitating snow retrievals from combined airborne cloud radar and millimeter-wave radiometer observations. J. Appl. Meteor. Climatol. 2008, 47, 1634-1650.

68. Draine, B.T.; Flatau, P.J. Discrete-dipole approximation for scattering calculations. J. Opt. Soc. Am. A 1994, 11, 1491-1499.

69. Xu, Y.-L.; Gustafson, B.A.S. A generalized multiparticle Mie-solution: Further experimental verification. J. Quant. Spectrosc. Radiat. Transf. 2001, 70, 395-419.

70. Battaglia, A.; Ajewole, M.O.; Simmer, C. Evaluation of radar multiple scattering effects in Cloudsat configuration. Atmos. Chem. Phys. 2007, 7, 1719-1730.

71. Matrosov, S.Y.; Battaglia, A. Influence of multiple scattering on CloudSat measurements in snow: A model study. Geophys. Res. Lett. 2009, 36, L12806, doi:12810.11029/12009GL038704.

72. Kulie, M.S.; Bennartz, R. Utilizing spaceborne radars to retrieve dry snowfall. J. Appl. Meteor. Climatol. 2009, 48, 2564-2580.

73. Hudak, D.; Rodriguez, P.; Donaldson, N. Validation of the CloudSat precipitation occurrence algorithm using the Canadian C band radar network. J. Geophys. Res. 2008, 113, D00A07, doi:10.1029/2008JD009992.

74. Turk, F.J.; Park, K.; Haddad, Z.; Rodriguez, P.; Hudak, D. Analysis of CloudSat-Based Snowfall Profiles Using C-band Ground Radar. In Proceedings of 5th International Precipitation Working Group Workshop, Hamburg, Germany, October 11-15, 2010.

75. Wang, N.-Y.; Ferraro, R.; Gopalan, K. Improvement of Cold Season Precipitation Retrievals through the Use of Field Campaign Data and High Frequency Microwave Radiative Transfer Model. In Proceedings of 4th International precipitation Working Group Workshop, Beijing, China, October 13-17, 2008; pp. 348-353.

76. Wang, N.-Y.; Gopolan, K.; Ferraro, R. Developing winter precipitation algorithm over land from satellite microwave and C3VP field campaign observations. In Proceedings of 5th International Precipitation Working Group Workshop, Hamburg, Germany, October 11-15, 2010.

77. Todini, G.; Rizzi, R.; Todini, E. Detecting precipitating clouds over snow and ice using a multiple sensors approach. J. Appl. Meteor. Climatol. 2009, 48, 1858-1867.

78. King, M.D.; Kaufman, Y.J.; Menzel, W.P.; Tanré, D. Remote sensing of cloud, aerosol, and water vapor properties from the Moderate Resolution Imaging Spectrometer (MODIS). IEEE Trans. Geosci. Remote Sens. 1992, 30, 2-27. 
79. Staelin, D.H.; Chen, F.W. Precipitation observations near 54 and $183 \mathrm{GHz}$ using the NOAA-15 satellite. IEEE Trans. Geosci. Remote Sens. 2000, 38, 2322-2332.

80. Staelin, D.H.; Surussavadee, C. Precipitation retrieval accuracies for geo-microwave sounders. IEEE Trans. Geosci. Remote Sens. 2007, 45, 3150-3159.

81. Surussavadee, C.; Staelin, D.H. Comparison of AMSU millimeter-wave satellite observations, MM5/TBSCAT predicted radiances, and electromagnetic models for hydrometeors. IEEE Trans. Geosci. Remote Sens. 2006, 44, 2667-2678.

82. Surussavadee, C.; Staelin, D.H. Millimeter-wave precipitation retrievals and observed-versussimulated radiance distributions: Sensitivity to assumptions. J. Atmos. Sci. 2007, 64, 3808-3826.

83. Marzano, F.S.; Cimini, D.; Memmo, A.; Montopoli, M.; Rossi, T.; Sanctis, M.D.; Lucente, M.; Mortari, D.; Michele, S.D. Flower constellation of millimeter-wave radiometers for tropospheric monitoring at pseudogeostationary scale. IEEE Trans. Geosci. Remote Sens. 2009, 47, 3107-3122.

84. Brandes, E.A.; Ikeda, K.; Zhang, G.; Schoenhuber, M.; Rasmussen, R.M. A statistical and physical description of hydrometeor distributions in Colorado snowstorms using a video disdrometer. J. Appl. Meteor. Climatol. 2007, 46, 634-650.

85. Heymsfield, A.J.; Bansemer, A.; Schmitt, C.; Twohy, C.; Poellot, M.R. Effective ice particle densities derived from aircraft data. J. Atmos. Sci. 2004, 61, 982-1003.

(C) 2011 by the authors; licensee MDPI, Basel, Switzerland. This article is an open access article distributed under the terms and conditions of the Creative Commons Attribution license (http://creativecommons.org/licenses/by/3.0/). 